\title{
Article \\ Comparison of the Sub-Critical Fluid Extraction of the Essential Oil of Turmeric (Curcuma longa L.) with That of Hydrodistillation
}

\author{
David Mc Gaw ${ }^{1}$ and Rosemarie Skeene ${ }^{2, *}$ \\ 1 Department of Chemical Engineering, Faculty of Engineering, St. Augustine Campus, \\ University of the West Indies, St. Augustine 999183, Trinidad and Tobago; drmcgaw@gmail.com \\ 2 School of Engineering, Technology and Architecture, North Campus, Miami Dade College, \\ Miami, FL 11380, USA \\ * Correspondence: rskeene@mdc.edu
}

Citation: Mc Gaw, D.; Skeene, R. Comparison of the Sub-Critical Fluid Extraction of the Essential Oil of Turmeric (Curcuma longa L.) with That of Hydrodistillation. Eng 2021, 2, 608-619. https://doi.org/ 10.3390/eng2040038

Academic Editors: Angeles Blanco Suarez and Antonio Gil Bravo

Received: 12 September 2021

Accepted: 18 November 2021

Published: 23 November 2021

Publisher's Note: MDPI stays neutral with regard to jurisdictional claims in published maps and institutional affiliations.

Copyright: (c) 2021 by the authors. Licensee MDPI, Basel, Switzerland. This article is an open access article distributed under the terms and conditions of the Creative Commons Attribution (CC BY) license (https:// creativecommons.org/licenses/by/ $4.0 /)$.

\begin{abstract}
Turmeric (Curcuma longa L.) is a spice plant grown in the tropics that contains both an essential oil and an oleoresin. The essential oil is important as a flavouring and has pharmaceutical properties, while the oleoresin is bright yellow in colour and has medicinal properties. The essential oil has traditionally been extracted by hydrodistillation/steam distillation with the total extract being extracted by solvent extraction and more recently by supercritical fluid extraction (SFE). The objective of the work described in this paper was to investigate the possibility of extracting the essential oil using sub-critical fluid extraction and to compare it with hydrodistillation. The experiments using hydrodistillation showed that unpeeled fresh turmeric was the preferred raw material, giving an oil yield of $\approx 6 \%$ dry weight basis, which is similar to that reported in the literature. The experimental programme on the extraction of the oil from dried unpeeled turmeric was carried out over a temperature range from 25 to $30{ }^{\circ} \mathrm{C}$ and pressures from 65 to 71 bar. Yields were generally higher than hydrodistillation (up to $\approx 9 \%$ dry weight basis) as were the compositions of the extracted oils. The preferred operating conditions were determined to be $25^{\circ} \mathrm{C}$ temperature and 65 bar pressure. Curcumin, the major component of the oleoresin, was not found in the oil, thereby demonstrating that the sub-critical extract is a pure essential oil. It is suggested that consideration be given to evaluating an SFE process whereby the essential oil is initially fully extracted under sub-critical fluid extraction conditions, after which the oleoresin is extracted separately by raising the pressure to $\approx 250$ bar.
\end{abstract}

Keywords: turmeric; hydrodistillation; sub-critical fluid extraction

\section{Introduction}

Many plant species in the tropics secrete complex chemicals, which are extracted and incorporated into various consumer products that may be classified as food flavours, nutraceuticals/pharmaceuticals, perfumes, and various other uses e.g., security sprays, insecticides, dyes, and colourings.

There are two basic types of these plant extracts: essential oils and oleoresins. Essential oils [1-3] are the volatile oils giving rise to the odour from the plant. Oleoresins [4], as the name implies, are a mixture of resinous material and oils that have much higher vapour pressures than the essential oils, melting at higher temperatures.

One of the major spices grown commercially in the tropics is that of turmeric (Curcuma longa L.), the total extract of which contains both an essential oil and oleoresin. The extract of turmeric is an aromatic liquid that is orange yellow in colour. This essential oil component is basically a mixture of volatile oils having the characteristic odour or flavour of turmeric [5], while the oleoresin component contains colouring matter [6]. In addition to their importance as a flavouring, the essential oils possess a wide variety 
of pharmaceutical properties in that they show activity as an antivenom agent (Ferreira et al. [7]), they exhibit good antioxidant properties (Jayaprakasha et al. [8]), and they are good anti-inflammatory agents, (Sandur et al. [9]). They are also reported to enhance immune function, promote blood circulation, accelerate toxin elimination, and stimulate digestion, as shown by Sacchetti et al. [10] and Raut and Karuppayal [11].

It is known that the volatile essential oils of turmeric can be extracted using steam distillation, hydrodistillation, and pressurised water extraction as reported by a number of investigators including Hu et al. [12], Jayaprakasha et al. [8], Manzan et al. [13], Braga and Miereles [14], Qin et al. [15], Shika Singh et al. [16], Awasthi and Dixit [17], Singh et al. [18], Raina et al. [19], and Angel et al. [20]). These studies have indicated that the quantum of volatile oil is usually in the range $1.5 \%$ to $6.0 \%$ on a dry weight basis.

A comprehensive review of reported research on the chemical composition and biological activities of the oil was subsequently carried out by Dosoky and Setzer [21]. In a further study Dosoky, Satyal, and Setzer [22] examined the variations in compositions of curcuma rhizome essential oils by the use of the Gas Chromatography Mass Spectrometry (GCMS) technique. They were compared to those reported in the literature and analysed by hierarchical cluster analysis. The various studies showed that the essential oil of curcuma rhizome is composed of a variety of sesquiterpenes many of which are specific for the species, including germacrone, $\alpha \beta$-turmerones, $\beta$-bisabolene, $\alpha$-curcumene, zingiberene, $\beta$-sesquiphellandrene, bisacurone, curcumenone, dehydrocurdione, procurcumadiol, bisacumol, curcumenol, isoprocurcumenol, epiprocurcumenol, procurcumenol, zedoaronediol, curlone, and tumeronol A and tumeronol B. However, the most abundant compounds were identified to be ar-turmerone, turmerone, and curlone, these being deemed to be the major quality components.

In a comparative study on the leaves and rhizomes, Ajaiyeoba et al. [23] extracted the essential oils by hydrodistillation, subjecting the oils to larvicidal toxicity studies. Their results showed that the rhizome oil was much more toxic than the leaves. Parveen et al. [24] extracted the turmeric oil from the leaves by hydrodistillation, following which the oil was subjected to antimicrobial tests. The results indicated that the oils extracted showed significant inhibitory activity against the tested organisms.

There have also been studies on the extraction of turmeric oil from turmeric rhizomes using supercritical fluid extraction (SFE). Thus, Li et al. [25] compared the extracts obtained by supercritical carbon dioxide and steam distillation. They concluded that SFE was better than steam distillation in terms of extraction time, power consumption, recovery, and purity. In their study, Gopalan et al. [26] measured the extraction rate as a function of pressure, temperature, flow rate, and particle size. The extraction rate increased with an increase in carbon dioxide flow rate and reduction of particle size; the effect of higher pressure and lower temperature favoured the extraction rate. The optimum pressure for the extracted oil was found to be 225 bar pressure. Chang et al. [27] extracted the oil of turmeric at a temperature of $60^{\circ} \mathrm{C}$ and 300 bar pressure. The oil was separated and purified by liquid-solid chromatography, NMR, and HPLC to obtain ar-turmerone and $\alpha$ and $\beta$ turmerone. Cheng et al. [28] extracted the turmeric oil by supercritical carbon dioxide and liquid solid chromatography and obtained $86 \%$ ar-turmerone. This ar-tumerone extract was subjected to several tests, and it exhibited significant antiproliferative activity with carcinoma cell lines. In these studies, it was noted that the basic extract from supercritical fluid extraction was a mixture of essential oil and oleoresin with the ar-turmerone being separated from the crude extract.

No published work on sub-critical extraction from turmeric using carbon dioxide was identified in the literature. However, a study on the comparison of sub-critical extraction of thymoquinone from black cumin Nigella sativa with that of hydrodistillation and steam distillation (Edris, Wawrzyniak, and Kelemba) [29] showed that the thymoquinone content of the extract from sub-critical extraction was much higher at $60.5 \%$ than that using hydrodistillation at $10.2 \%$ and steam distillation at $23.7 \%$, respectively. In another study whereby the sub-critical extraction of Chinese quince seed was compared with Soxhlet 
extraction and SFE, Wang et al. [30] found that the oil extracted using sub-critical extraction had the highest yield at $27.8 \%$ with higher unsaturated acid and $\alpha$ tocopherol contents.

There are two basic objectives of the work described here:

(a) To evaluate the potential for using carbon dioxide extraction of turmeric under subcritical conditions to produce a pure essential oil without oleoresin contamination.

(b) To compare sub-critical carbon dioxide extraction with the traditional process of hydrodistillation as an alternative commercial operation.

The approach taken was to produce the essential oil from bench-scale hydrodistillation and sub-critical fluid extraction units and to compare the oil yields and compositions. The experimental program also aimed to identify the best operating conditions for subcritical extraction.

\section{Materials and Methods}

\subsection{Raw Material Supply and Preparation}

In order to minimise raw material variations, all turmeric was obtained from one consistent supplier in Rousillac, South Trinidad. The turmeric was first washed to remove mud and any loose plant material. The washed turmeric rhizomes were placed on paper towels and allowed to air dry in an air-conditioned environment at $25^{\circ} \mathrm{C}$ for $24 \mathrm{~h}$, after which they were cut into $2 \mathrm{~mm}$ thick discs.

Two drying techniques were tested initially: the first being a Unitemp drying oven capable of drying over ranges of temperatures from 35 to $65^{\circ} \mathrm{C}$. The second was an Armfield SB4 freeze dryer with an attached precision scientific vacuum pump. This was used to freeze dry samples of turmeric for $48 \mathrm{~h}$ at a temperature of $-40{ }^{\circ} \mathrm{C}$ and at a vacuum of 18-20 inches of mercury. No significant difference in yields was measured between the two, so the Unitemp drying oven was used to dry the turmeric for all subsequent experiments except in two cases for hydrodistillation, where the fresh turmeric was used. Drying was for a period of $26 \mathrm{~h}$ at a temperature of $55^{\circ} \mathrm{C}$ to attain the equilibrium moisture content, as shown by Mc Gaw et al. [31].

At the end of drying, the turmeric was milled and ground to a particle size of approximately $850 \mu \mathrm{m}$ using a Straub Model 4E Grinding Mill. Then, the ground turmeric was passed through a sieve of mesh size $850 \mu \mathrm{m}$, placed in individual plastic bags, and stored in airtight desiccators in a cupboard prior to extraction.

Moisture determination of both the fresh and dried turmeric were measured in duplicate by the official AOAC method 986.21 (Dean and Stark) for moisture in spices. Fresh turmeric was found to contain $86.9 \%$ moisture on a wet basis and $3.5 \%$ dried material on a wet basis.

\subsection{Extraction Apparatus}

\subsubsection{Hydrodistillation}

Hydrodistillation was carried out in a standard Clevenger apparatus. The apparatus consisted of a $1000 \mathrm{~mL}$ round-bottom flask, which was heated by a heating mantle. The flask held water and the turmeric material to be hydrodistilled. The Clevenger apparatus, fitted into the round-bottom flask, consisted of a vertical tube combined with a condenser and measuring tube with stopcock. A return tube for the aqueous part of the distillate connected the bottom of the measuring tube and the vertical tube. The Clevenger apparatus enabled the distillation process by boiling and condensing the water/turmeric mixture to separate the oil from the turmeric. The oil was collected in the measuring tube, it being immiscible with water, and it was withdrawn using the stopcock. The volume was measured, after which its composition was analysed on the Agilent Technologies $6890 \mathrm{~N}$ gas chromatograph-mass spectrometer (GCMS) with its associated 5973 inert mass selective detector and 7683 series injector in the Extraction Lab, Department of Chemical Engineering the University of the West Indies, St. Augustine, Trinidad and Tobago. 


\subsubsection{Sub-Critical Fluid Extraction}

All sub-critical fluid extraction experiments were carried out using an Applied Separations laboratory model Spe-ed Supercritical Fluid Extraction (SFE) unit with carbon dioxide as the extraction fluid. The extraction vessel, manufactured by Thar Designs Inc, was made of stainless steel and could be operated at a maximum pressure of 10,000 psi. The Spe-ed SFE unit used carbon dioxide as its operating fluid, which was supplied to the unit from a carbon dioxide cylinder outfitted with a dip tube to facilitate only liquid carbon dioxide to be supplied to the SFE unit. Additionally, a chiller was used to keep the liquid carbon dioxide cool as it entered the SFE unit. However, all experiments were carried out at temperatures and pressures below the critical point $\left(72.9\right.$ bar pressure, $31^{\circ} \mathrm{C}$ temperature), effectively using liquid carbon dioxide. The flow rate of carbon dioxide through the bed was $5 \mathrm{~L}$ per minute, which is equivalent to a superficial velocity of $\approx 1 \mathrm{~L}$ per minute per $\mathrm{cm}^{2}$ through the bed.

\subsection{Analysis of Oil Samples}

The Agilent Technologies $6890 \mathrm{~N}$ gas chromatograph-mass spectrometer system was again used to analyse samples and standards. The column used for all the analyses was an Agilent HP5-ms $30 \mathrm{~m}$ capillary column with an internal diameter of $0.25 \mu \mathrm{m}$ and an external diameter of $250 \mu \mathrm{m}$. This instrument was equipped with the National Institute for Standard and Technology (NIST) peer-reviewed and fully evaluated mass spectral library to identify unknown spectra. The library search report identified each component on the spectrum by its peak number, retention time (RT), area \% (area under the peak), library name or ID, reference number, CAS number (Chemical Abstracts Service number-each number represents only one substance), and the quality.

The essential oils obtained sub-critically were also quantified using ar-turmerone as an internal standard. It was the only essential oil of the six most abundant essential oils collected from the extractions that was available to be purchased as a pure standard. Consequently, the masses of each of the six essential oils were quantified relative to that of ar-turmerone.

\subsection{Experimental Programme}

\subsubsection{Hydrodistillation}

Four hydrodistillation experiments were carried out whereby the preparation of the raw material turmeric was varied. In each case, $100 \mathrm{~g}$ of material was prepared, the first two experiments being on fresh turmeric (peeled and unpeeled) and the latter two on dried turmeric (peeled and unpeeled). Each experiment was run for $180 \mathrm{~min}$, after which it was deemed that extraction had been completed. The essential oil was separated from the bulked distillate by virtue of their immiscibility, and the volume collected was measured in each case. All experiments were in duplicate.

\subsubsection{Sub-Critical Fluid Extraction}

The critical point for carbon dioxide is at 72.9 bar pressure and $31{ }^{\circ} \mathrm{C}$ temperature (Mukhopadhyay [32]), so all experiments were carried out over ranges of values just below these figures, specifically 65 to 71 bar pressure and 25 to $30^{\circ} \mathrm{C}$ temperature. Approximately $20 \mathrm{~g}$ of dried turmeric was charged to the extraction vessel for each experiment with the extract being collected every 5 min for mass and composition determination. All experiments were in duplicate. Since the objective of the work was to carry out a comparison of sub-critical fluid extraction with hydrodistillation, all experiments were carried out for a fixed time at the upper end of that which could reasonably be used commercially, $300 \mathrm{~min}$.

\section{Results}

\subsection{The Initial Drying Experiments}

The initial drying experiments to compare oven drying for $26 \mathrm{~h}$ at $55^{\circ} \mathrm{C}$ and freeze drying were carried out on sub-critical extraction at 65 bar pressure and $25^{\circ} \mathrm{C}$ for a period 
of $60 \mathrm{~min}$. The oven dried material had a yield of $1.9 \%$ and the freeze-dried material had a yield of $2.0 \%$. Since oven drying is a more practical process for commercial activities than freeze drying and there was no significant difference in the extraction yields from the two drying processes, oven drying was used in the main experimental programme.

\subsection{The Extraction of Turmeric Oil by Hydrodistillation}

The hydrodistillation experiments distilling oil from $100 \mathrm{~g}$ samples of fresh peeled and unpeeled turmeric gave rise to an average of $0.81 \mathrm{~mL}$ oil being collected. The reference to the results shown in Table 1 shows little variation in the yield of oil obtained from the fresh turmeric when compared to the dried turmeric. On looking at the analysis of the oils, the peeled turmeric in both the fresh and dried samples yielded more components than the unpeeled turmeric samples. This may suggest some inhibition on the part of the turmeric skin on the extraction of the turmeric oil from the turmeric in the hydrodistillation process; however, no further investigations were undertaken in this respect. All further extractions used unpeeled turmeric.

Table 1. Hydrodistillation extraction results.

\begin{tabular}{|c|c|c|}
\hline Raw Material & $\begin{array}{l}\text { Volume of Oil } \\
\text { Collected in mLs }\end{array}$ & Components in Hydrodistilled Oil \\
\hline Fresh Peeled Turmeric & $0.81 \mathrm{~mL}$ & $\begin{array}{l}\alpha \text {-phellandrene, } 3 \text {-carene, 1,8-cineole, } \\
\text { ar-turmerone, turmeronecaryophyllene, } \\
\text { benzyl benzoate }\end{array}$ \\
\hline Fresh Unpeeled Turmeric & $0.80 \mathrm{~mL}$ & $\begin{array}{l}\text { 1,8-cineole, zingiberene, } \\
\beta \text {-sesquiphellandrene, ar-turmerone, } \\
\text { turmerone, curlone }\end{array}$ \\
\hline Dried Peeled Turmeric & $0.82 \mathrm{~mL}$ & $\begin{array}{l}\text { 1,8-cineole, 3-carene, zingiberene, } \\
\text { curlone, ar-turmerone, } \\
\text { turmeronecis-bisabolene, p-cymen-9-ol }\end{array}$ \\
\hline Dried Unpeeled Turmeric & $0.80 \mathrm{~mL}$ & $\begin{array}{l}\text { 1,8-cineole, caryophyllene, 3-carene, } \\
\text { zingiberene, turmerone }\end{array}$ \\
\hline
\end{tabular}

The average quantum of oil collected converts to a yield of $6.2 \%$ on a dry weight basis.

It is important to note that whereas it may be anticipated that the drying process may reduce oil collection, further reference to Table 1 shows that the volumes of oil collected were of the same order as those using undried fresh material.

\subsection{Extraction of Turmeric Oil by Subcritical Fluid Extraction}

All experiments on sub-critical extraction were carried out on unpeeled dried turmeric. The extraction curves for sub-critical extraction are shown in Figures 1-3 as plots of percentage yield on a dry weight basis against extraction time at the various temperatures and pressures over the $5 \mathrm{~h}$ extraction time. The extractions were done in duplicate, so the extraction curves are plotted as the average of the two, the associated standard deviations (S.D) are given.

A pale-yellow liquid extract was obtained in all cases. For comparative purposes, the overall yields are detailed in Table 2.

The reference to Table 2 shows that higher yields were generally obtained at lower temperatures. The highest yield, $\approx 9.0 \%$, was obtained at a temperature of $25^{\circ} \mathrm{C}$ and a pressure of 65 bar.

Six key components were identified as being the most abundant in the oils extracted, namely ar-turmerone, curlone, turmerone, $\beta$-sesquiphellandrene, zingiberene, and $\alpha$ curcumene. The reference to Table 3 shows that the extracts obtained at the lower temperatures contained a higher percentage of the six key components. Typical component extraction curves for the three experiments carried out at $25^{\circ} \mathrm{C}$ at varying pressures are shown in Figures 4-6. These three were chosen for presentation because of their higher yields, the associated standard deviations (S.D.) are given. 


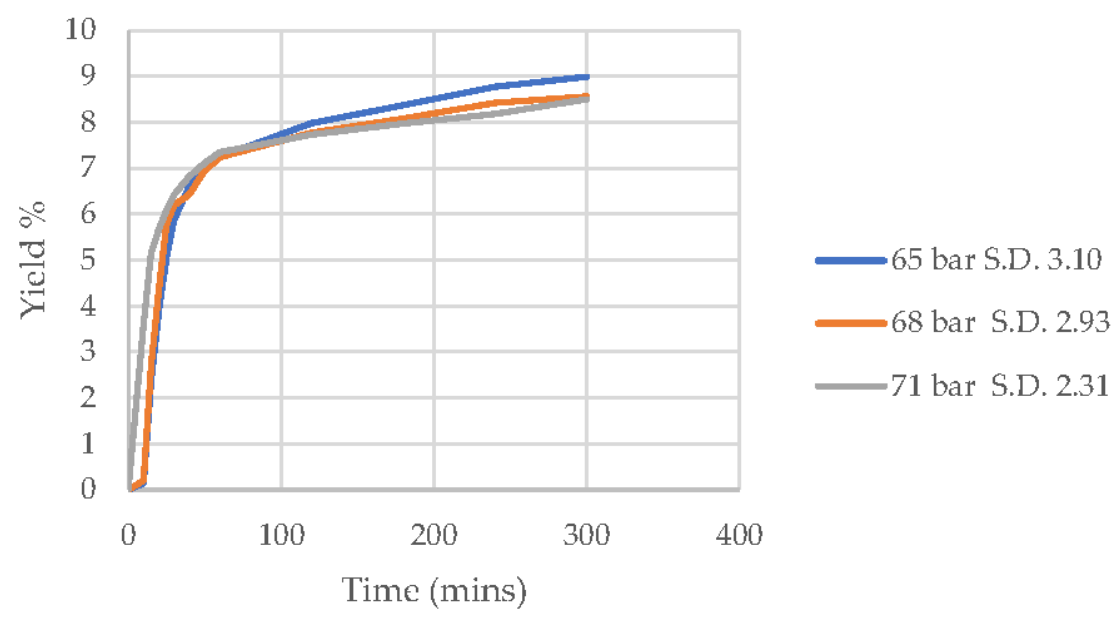

Figure 1. Sub-critical extraction curves for 65,68 and 71 bar pressures at $25^{\circ} \mathrm{C}$.

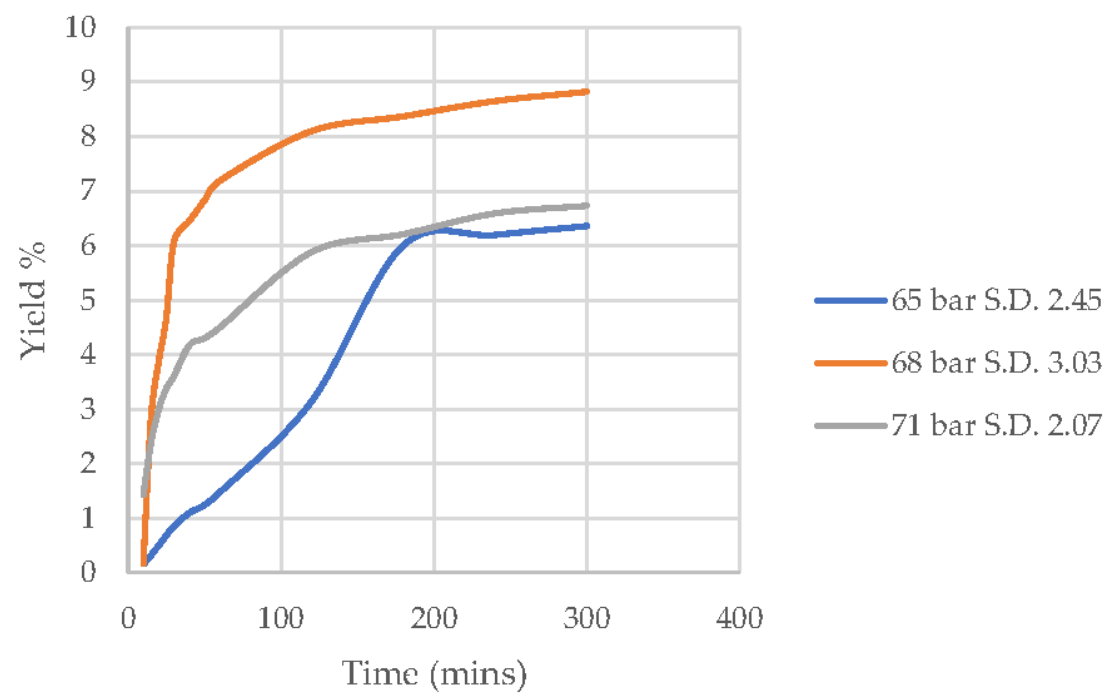

Figure 2. Sub-critical extraction curves for 65,68 and 71 bar pressures at $27^{\circ} \mathrm{C}$.

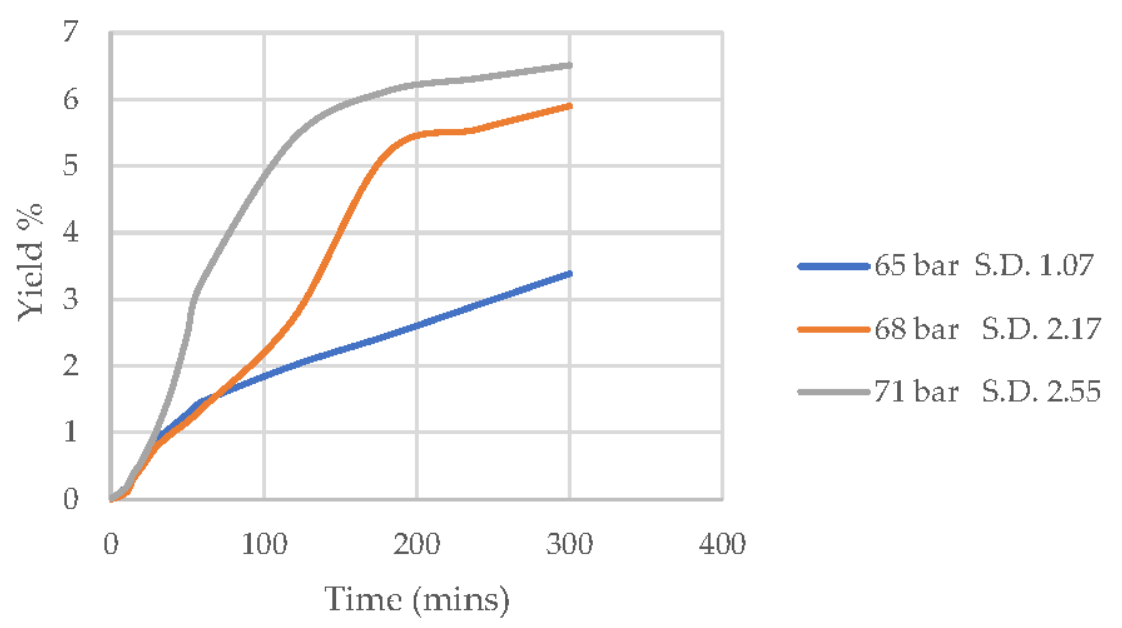

Figure 3. Sub-critical extraction curves for 65,68 , and 71 bar pressures at $30{ }^{\circ} \mathrm{C}$. 
Table 2. Average yields of oil as a function of temperature and pressure.

\begin{tabular}{ccc}
\hline Temperature in ${ }^{\circ} \mathbf{C}$ & Pressure in Bar & Average Yield \% Dry Weight Basis \\
\hline 25 & 65 & 8.97 \\
25 & 68 & 8.58 \\
25 & 71 & 8.52 \\
27 & 65 & 6.41 \\
27 & 68 & 8.82 \\
27 & 71 & 6.93 \\
30 & 65 & 3.39 \\
30 & 68 & 5.90 \\
30 & 71 & 6.51 \\
\hline
\end{tabular}

Table 3. The percentage of key components as a function of temperature and pressure.

\begin{tabular}{ccc}
\hline Temperature in ${ }^{\circ} \mathbf{C}$ & Pressure in Bar & $\begin{array}{c}\text { The \% of the Key Components Determined } \\
\text { in the Extract }\end{array}$ \\
\hline 25 & 65 & 70.9 \\
25 & 68 & 50.9 \\
25 & 71 & 53.2 \\
27 & 65 & 54.2 \\
27 & 68 & 47.2 \\
27 & 71 & 46.2 \\
30 & 65 & 39.6 \\
30 & 68 & 46.7 \\
30 & 71 & 44.9 \\
\hline
\end{tabular}

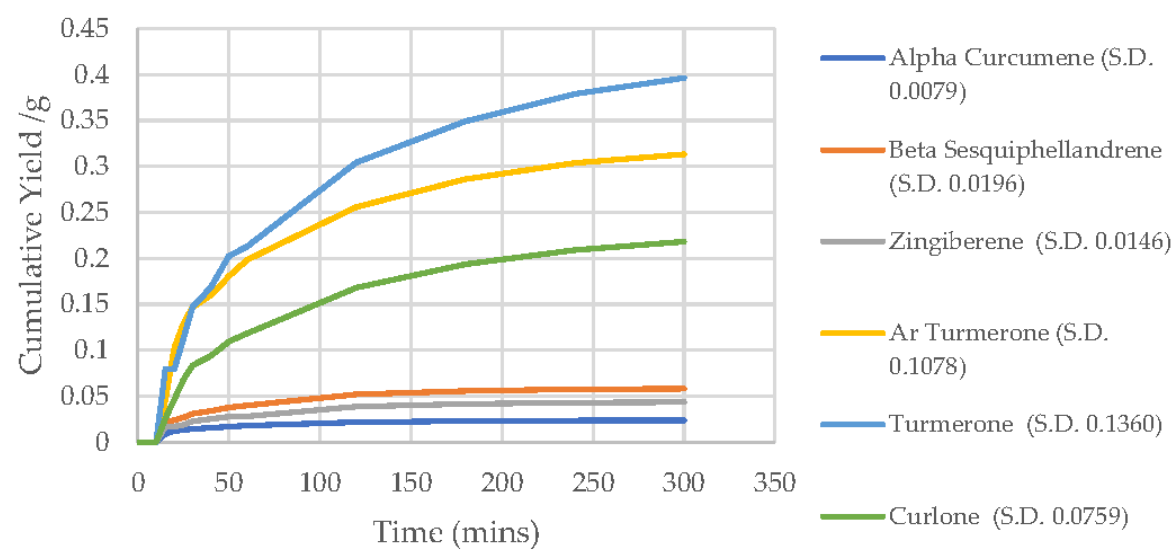

Figure 4. Sub-critical component extraction curves at $25^{\circ} \mathrm{C} 65$ bar.

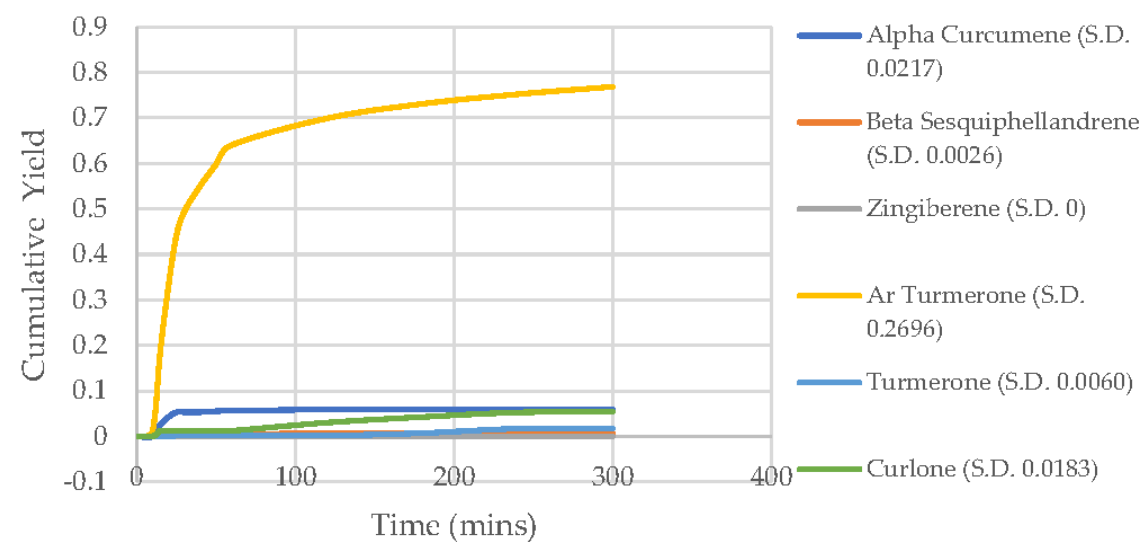

Figure 5. Sub-critical component extraction curves at $25^{\circ} \mathrm{C} 68$ bar. 


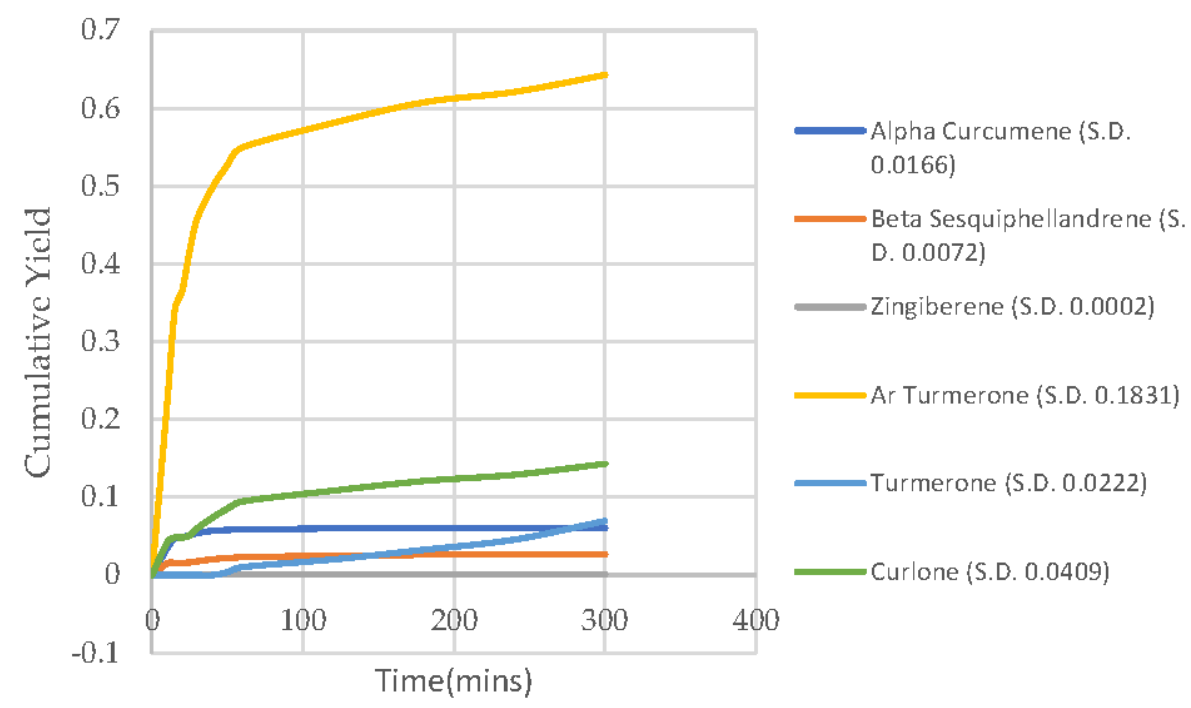

Figure 6. Sub-critical component extraction curves at $25^{\circ} \mathrm{C} 71$ bar.

Figures 4- 6 show that the extraction conditions of $25{ }^{\circ} \mathrm{C}$ and 65 bar gave the largest quantity of oil obtained for four of the key components: namely, $\beta$-sesquiphellandrene, zingiberene, turmerone, and curlone. Ar-turmerone was found to be the most abundant component extracted at all conditions. It should be noted that $\alpha$ curcumene, $\beta$ sesquiphellandrene, and zingiberene were exhaustively extracted over the $5 \mathrm{~h}$ period, as evidenced by the increase and then plateau seen by each component at all conditions. Similar plateaus were not evident for ar-turmerone, turmerone, and curlone.

\section{Discussion}

\subsection{Hydrodistillation}

Table 1 shows that the four different preparations (peeled/unpeeled, fresh/dried) gave similar yields of $\approx 0.8 \mathrm{~mL}$ essential oil from $100 \mathrm{~g}$ of fresh turmeric. This is equivalent to $6.2 \%$ extraction on a dry weight basis. Table 1 also shows that the oils extracted from the peeled material contained more components than the unpeeled material, but these additional components did not enhance the quality of the oil. This indicates that the additional process of peeling is unnecessary. It is also not practical for a commercial operation. Comparison of the hydrodistillation experiments with dried and undried materials gave both similar yields and compositions, suggesting that the additional process of drying is also unnecessary.

The yields obtained compared well with those reported in the literature. Thus, the yield is the same as that obtained by Raina [19]. However, Awasthi and Dixit [17] reported yields of only about half that value. In investigating the essential oil yields from eight starchy Curcuma species, using the Clevenger apparatus, Angel et al. [20] obtained oil yields varying from 0.38 to $1.4 \mathrm{~mL} / 100 \mathrm{~g}$ samples, thereby showing that the essential oil yields varied between species. This was subsequently confirmed by Dosoky, Satyal, and Setzer [22]. However, it must be recognised that other factors, possibly soil, climate, and geographical influences, may play a part in the yield of turmeric oil obtained.

Notwithstanding the fact that the oils obtained from the peeled turmeric contained a number of extra components, the oil obtained from hydrodistillation of the fresh unpeeled turmeric contained the same components as quoted in the literature.

\subsection{Sub-Critical Fluid Extraction}

All sub-critical extraction experiments were carried out on dried material. When using fresh material, the water interferes with the extraction process.

The summary of total yields detailed in Table 2 shows the highest yields being obtained at the lowest temperature, $25^{\circ} \mathrm{C}$, the highest yield of all being at $25^{\circ} \mathrm{C}$ and 65 bar pressure. 
In terms of the overall composition of the six major quality components, the data taken from Figures 4-6 show the highest cumulative percentage at 71\%, also when operating at $25{ }^{\circ} \mathrm{C}$ and 65 bar pressure, with $51 \%$ at $25{ }^{\circ} \mathrm{C}$ and 68 bar and $53.2 \%$ at $25^{\circ} \mathrm{C}$ and 71 bar. This percentage varied from $39.6 \%$ to $54.2 \%$ for the other operating conditions investigated with the lower values being at the higher pressures and temperatures.

When the extraction curves for the individual components for this set of conditions, as shown in Figure 4, are compared to those operating under the other conditions investigated i.e., Figures 5 and 6, it is also seen that whereas the highest yields are always of arturmerone, there is a far bigger spread of the curlone and turmerone components when operating at $25^{\circ} \mathrm{C}$ and 65 bar pressure.

Therefore, it may be concluded that the optimum operating conditions for the extraction of the essential oil from oven dried turmeric are $25^{\circ} \mathrm{C}$ and 65 bar pressure, both from the point of view of overall yield and essential oil composition. However, if the objective is to obtain ar-turmerone, then the results show that a higher pressure should be used.

All extractions were carried out over a $5 \mathrm{~h}$ period, and whereas many yield vs. time curves showed close to complete extraction, a few had not quite levelled off to that state. This was particularly true when operating at $30{ }^{\circ} \mathrm{C}$; for $30{ }^{\circ} \mathrm{C}$ and 65 bar, it was still rising steadily after $5 \mathrm{~h}$, which are conditions that are clearly unsuitable for commercial extraction.

In commercial practice, extraction would be cut off rather earlier, typically $3 \mathrm{~h}$ when $\approx 90 \%$ of the extraction had been collected. The extra $2 \mathrm{~h}$ operating cost would not be worth the collection of the last $\approx 10 \%$.

It is important to note that no curcumin was obtained in any of the sub-critically extracted oils. Therefore, the sub-critical oils were pure essential oils uncontaminated by the turmeric oleoresin.

\subsection{Comparison of Hydrodistillation with Sub-Critical Fluid Extraction}

The overall yields obtained from the hydrodistillation experiments, as indicated in Table 1 , gave a yield of $\approx 6.2 \%$ dry weight basis, with preferred raw material being unpeeled fresh turmeric. The yields from the sub-critical extraction of unpeeled dried material, as detailed in Table 2, showed yields varying with operating conditions from $3.4 \%$ to $9.0 \%$ on a dry weight basis, with the highest yields at the lowest temperature of $25^{\circ} \mathrm{C}$. Therefore, sub-critical fluid extraction is preferred to hydrodistillation on the basis of yield.

The component distribution identified in the hydrodistilled oil was fairly comparable to that identified in the sub-critically extracted oils, as shown in Table 3. Thus, the key components identified in the sub-critical extractions as being the most abundant in the extracts were $\alpha$-curcumene, $\beta$-sesquiphellandrene, zingiberene, ar-turmerone, turmerone, and curlone. However, whereas one of the key components was not identified at all in the hydrodistilled oils, the other five key components were present. Several components other than the key components identified in the hydrodistilled oil were also found in the subcritical oils, but in low concentrations. Overall, the sub-critical extractions provided a far superior product both in terms of quality and yield. Therefore, in terms of commercialising the process, subcritical extraction rather than hydrodistillation is the preferred method of extraction.

Table 4 also indicates that the need to dry the turmeric prior to sub-critical fluid extraction does not seem to adversely affect the product quality.

\subsection{Implications of Results}

The results show that sub-critical fluid extraction can give a higher yield than hydrodistillation and that the extract is of higher quality. The extracts in each case are pure essential oils uncontaminated with oleoresin.

Therefore, in terms of commercial application, the production of the essential oil of turmeric by sub-critical extraction is preferred, but it is appropriate that a financial comparison be made involving both capital and operating costs. In determining the operation costs of sub-critical extraction, the superficial flow rate of $\approx 1 \mathrm{~L}$ per min per $\mathrm{cm}^{2}$ 
could be used as the flow rate of carbon dioxide through the bed. This will be recycled directly during the extraction process so that only carbon dioxide will be needed to replace that lost in the shut down and start-up stages between batches. Figure 1 shows an extraction rate of $8 \%$ after $180 \mathrm{~min}$ for the preferred conditions with significantly reducing extraction after that time, so $180 \mathrm{~min}$ is suggested as a practical extraction time. Since the crosssectional area of the commercial unit will be rather larger than the experimental unit, there may be issues of carbon dioxide distribution in the bed. Therefore, a lower extraction rate should be used in the comparative financial analyses to allow for this; $6 \%$ is suggested.

Table 4. Comparison of hydrodistilled oil to sub-critically extracted oil from turmeric.

\begin{tabular}{|c|c|c|}
\hline $\begin{array}{c}\text { Type of Material } \\
\text { Components }\end{array}$ & $\begin{array}{c}\text { Hydrodistilled Fresh } \\
\text { Turmeric } \\
\text { Quantity of Component/g }\end{array}$ & $\begin{array}{c}\text { Sub-Critical Oven Dried } \\
\text { Turmeric } \\
25^{\circ} \mathrm{C} 65 \mathrm{Bar} \\
\text { Quantity of Component/g }\end{array}$ \\
\hline$\alpha$ curcumene & 0 & 0.046 \\
\hline B sesquiphellandrene & 0.013 & 0.109 \\
\hline zingiberene & 0.016 & 0.089 \\
\hline ar-turmerone & 0.124 & 0.475 \\
\hline turmerone & 0.365 & 0.292 \\
\hline curlone & 0.122 & 0.307 \\
\hline
\end{tabular}

However, in addition, it can provide the basis of a process whereby the essential oil and oleoresin could be produced separately in a single operation. Thus, in a supercritical fluid extraction process, the first period of the operation would be carried out under subcritical conditions to produce the pure essential oil. Once the oil extraction is complete, the pressure would be increased to typically 250 bar pressure to extract the oleoresin. This possibility is being examined in a separate study.

\section{Conclusions}

It may be concluded that the preferred raw material for the hydrodistillation of turmeric rhizomes is fresh unpeeled material. The yield of the oil obtained in the experimental programme at $\approx 6.2 \%$ on a dry weight basis and the composition of the hydrodistilled oil are supported in the literature.

The yields of essential oil from the sub-critical fluid extraction of oil using carbon dioxide normally varied from $\approx 6 \%$ to $\approx 9 \%$ with the highest yields being at the lowest temperature used in the experimental program i.e., $25^{\circ} \mathrm{C}$. The oils extracted by sub-critical fluid extraction contained the quality components, i.e., ar-turmerone, curlone, turmerone, $\beta$ sesquiphellandrene, zingiberene, and $\alpha$-curcumene to varying degrees with ar-turmerone being the major component under all conditions. No curcumin, the major component of the oleoresin, was detected in any of the extracts, thereby indicating that sub-critical fluid extraction produced a pure essential oil.

The preferred extraction conditions for sub-critical fluid extraction were $25^{\circ} \mathrm{C}$ temperature and 65 bar pressure. Sub-critically extracted oil is preferred, as it gave a higher overall yield than hydrodistillation with higher concentrations of the quality components, as shown in Table 4.

It is recommended that an analysis of the capital and operating cost of a typical commercial sub-critical fluid extraction process is carried out and compared with hydrodistillation. Secondly, a single supercritical fluid extraction process should be investigated to separate the essential oil and the oleoresin in which the first step in the extraction process is operated at $25^{\circ} \mathrm{C}$ and 65 bar pressure until the essential oil is fully extracted, after which the pressure is increased to typically 250 bar pressure to extract the oleoresin.

Author Contributions: Experimental work, R.S.; Supervision, D.M.G. All authors have read and agreed to the published version of the manuscript.

Funding: This research received no external funding. 
Data Availability Statement: McGaw, David; Skeene, Rosemarie (2021), “Data for Journal article on Sub critical /Hydrodistillation comparison", Mendeley Data, V2, doi: 10.17632/fw843kzmc5.2.

Acknowledgments: The authors wish to thank Naresh Birju for graciously supplying the raw material used in this research.

Conflicts of Interest: The authors declare no conflict of interest.

\section{References}

1. King, K. Packaging and storage of herbs and spices. In Handbook of Herbs and Spices; Peter, K.V., Ed.; Woodhead Publishing: Cambridge, UK, 2006; Volume 3, pp. 86-102, ISBN 978-1-84569-017-5.

2. Ríos, J.L. Chapter 1-Essential Oils: What They Are and How the Terms Are Used and Defined. In Essential Oils in Food Preservation, Flavor and Safety; Preedy, V.R., Ed.; Academic Press: San Diego, CA, USA, 2015; pp. 3-10, ISBN 9780124166417.

3. Turek, C.; Stintzing, F.C. Stability of Essential Oils: A Review. Compr. Rev. Food Sci. Food Saf. 2013, 12, 40-53. [CrossRef]

4. Moyler, D.A. Oleoresins, tinctures and extracts. In Food Flavourings; Ashurst, P.R., Ed.; Springer: Boston, MA, USA, 1991; pp. 54-86, ISBN 978-1-4612-7838-2.

5. ICAR-Indian Institute of Spices Research. Pragati (Turmeric). Available online: http:/ / spices.res.in (accessed on 20 January 2019).

6. Hewlings, S.J.; Kalman, D.S. Curcumin: A Review of its' Effects on Human Health. Foods 2017, 6, 92. [CrossRef] [PubMed]

7. Ferreira, L.A.F.; Henriques, O.; Andreoni, A.S.; Glaucio, V.R.F. Antivenom and biological effects of ar -turmerone isolated from Curcuma longa. Toxicon 1992, 30, 1211-1218. [CrossRef]

8. Jayaprakasha, G.; Jena, B.S.; Negl, P.S.; Sakariah, K. Evaluation of Antioxidant Activities and Antimutagenicity of Turmeric Oil: A Byproduct from Curcumin Production. Z. Naturforsch. C J. Biosci. 2002, 57, 828-835. [CrossRef] [PubMed]

9. Sandur, S.; Pandey, M.; Sung, B.; Ahn, K.S.; Murakami, A.; Gautam, S.; Limtrakul, P.; Badmaev, V.; Aggarwal, B. Curcumin, demethoxycurcumin, bisdemethoxycurcumin, tetrahydrocurcumin, and tumerones differentially regulate anti-inflammatory and antiproliferative responses through a ROS independent mechanism. Carcinogenesis 2007, 28, 1765-1773. [CrossRef] [PubMed]

10. Sacchetti, G.; Maielti, S.; Muzzoli, M.; Scaglianti, M.; Manfredini, S.; Radice, M.; Bruni, R. Comparative Evaluation of 11 Essential Oils of different Origin as Functional Oxidants, Antiradicals and Antimicrobials in Foods. Food Chem. 2005, 91, 621-632. [CrossRef]

11. Raut, J.S.; Karuppayal, S.M. A Status Review on the Medical Properties of Essential Oils. Industrial Crops and Products. 2014, 52, 250-264. [CrossRef]

12. Hu, Y.; Du, Q.; Tang, Q. Determination of the Chemical Constituents of the Volatile Oil from Curcuma Longa by GCMS. Se Pu. 1998, 16, 528-529. (In Chinese) [PubMed]

13. Manzan, A.F.; Toniolo, F.; Bredow, E.; Pinheiro, N. Extraction of Essential oil and pigments from Curcuma longa L. by Steam Distillation and Extraction with Volatile solvents. J. Agric. Food Chem. 2003, 51, 6802-6807. [CrossRef]

14. Braga, M.; Meireles, M.A. Accelerated Solvent Extraction and Fractional Extraction to Obtain the Curcuma longa L. Volatile Oil and Oleoresin. J. Food Process Eng. 2007, 30, 501-521. [CrossRef]

15. Qin, N.Y.; Yang, F.Q.; Wang, Y.T.; Li, S.P. Quantitative Determination of 8 Components in Rhizome and Tuberous Root of Curcuma Longa using Pressurized Liquid Extraction and Gas Chromatography-Mass Spectrometry. J. Pharm. Biomed. Anal. 2007, 43, 486-492. [CrossRef]

16. Singh, S.; Panda, M.K.; Enketeswar, S.; Sanghamitra, N. Chemical Composition of Leaf and Rhizome Oil of an elite genotype of Curcuma longa L from the south eastern Ghats of Orissa. J. Pharm. Res. 2010, 3, 1630-1633.

17. Awasthi, P.K.; Dixit, S.C. Chemical Composition of Curcuma Longa L, Leaves and Rhizome Oil from the Plains of Northern India. J. Young Pharm. 2009, 1, 312-316. [CrossRef]

18. Singh, G.; Kapoor, I.P.S.; Singh, P.; de Heluani, C.; de Lampasona, M.; Catalan, C. Comparative Study of Chemical Composition and Antioxidant Activity of Fresh and Dry Rhizomes of Turmeric (Curcuma Longa L.). Food Chem. Toxicol. 2010, 48, $1026-1031$. [CrossRef] [PubMed]

19. Raina, V.K.; Srivastava, S.A.; Syamsundar, K. Rhizome and Leaf Oil Composition of Curcuma Longa from the lower Himalayan region of Northern India. J. Essent. Oil Res. 2005, 17, 556-559. [CrossRef]

20. Angel, G.R.; Menon, N.; Vimala, B.; Nambisan, B. Essential Oil Composition of Eight Starchy Curcuma Species. Ind. Crops Prod. 2014, 60, 233-238. [CrossRef]

21. Dosoky, N.S.; Setzer, W.N. Chemical Composition and Biological Activities of Essential Oils of Curcuma Species. Nutrients 2018, 10, 1196. [CrossRef]

22. Dosoky, N.S.; Satyal, P.; Setzer, W.N. Variations in the Volatile Compositions of Curcuma Species. Foods 2019, 8, 53. [CrossRef]

23. Ajaiyeoba, E.O.; Sama, W.; Essien, E.E.; Olayemi, J.O.; Ekundayo, O.; Walker, T.M.; Setzer, W.N. Larvicidal Activity of Turmerone Rich Essential Oils of Curcuma longa L. Leaf and Rhizome From Nigeria on Anopheles Gambiae. Pharm. Biol. 2008, 46, $279-282$. [CrossRef]

24. Parveen, Z.S.; Nawaz, S.; Siddique, S.; Shahzad, K. Composition and Antimicrobial activity of the Essential oil from the leaves of Curcuma longa L. Kasur Variety. Ind. J. Pharm. Sci. 2013, 75, 117-122. [CrossRef]

25. Li, R.; Xiang, C.; Zhang, X.; Guo, D.; Ye, M. Chemical Analysis of the Chinese Herbal Medicine Turmeric (Curcuma longa L.). Curr. Pharm. Anal. 2010, 6, 256-268. [CrossRef] 
26. Gopalan, B.; Goto, M.; Kodama, A.; Hirose, T. Supercritical Fluid Extraction of Turmeric (Curcuma Longa L.). J. Agric. Food Chem. 2000, 4, 2189-2192. [CrossRef]

27. Chang, L.H.; Jong, T.T.; Huang, H.S.; Nien, Y.F.; Chang, C.M.J. Supercritical carbon dioxide Extraction of turmeric oil from Curcuma longa Linn and purification of turmerones. Sep. Purif. Technol. 2006, 47, 119-125. [CrossRef]

28. Cheng, S.-B.; Wu, L.-C.; Hsieh, Y.-C.; Wu, C.-H.; Chan, Y.-J.; Chang, L.-H.; Chang, C.-M.J.; Hsu, S.-L.; Teng, C.L.; Wu, C.-C. Supercritical Fluid Extraction of Ar Turmerone from Curcuma Longa L. J. Agric. Food Chem. 2012, 60, 9620-9630. [CrossRef] [PubMed]

29. Edris, A.E.; Wawrzyniak, P.; Kalemba, D. Sub-critical $\mathrm{CO}_{2}$ Extraction of a volatile oil-rich Fraction from the Seeds of Nigella sativa for potential pharmaceutical and neutraceutical applications. J. Essent. Oil Res. 2018, 30, 84-91. [CrossRef]

30. Wang, L.; Wu, M.; Liu, H.-M.; Ma, Y.-X.; Wang, X.-D.; Qin, G.-Y. Sub-critical Fluid Extraction of Chinese Quince Seed, Optimization and Product Characterization. Molecules 2017, 22, 528. [CrossRef]

31. McGaw, D.; Maharaj, L.; Commissiong, E. The Effects of Drying conditions on the quality of Turmeric (Curcuma longa L.); International Drying Symposium (IDS): Halkidiki, Greece, 1998.

32. Mukhopadhyay, M. Natural Extracts Using Supercritical Carbon Dioxide; CRC Press: Boca Raton, FL, USA, 2000; ISBN 0-8493-0819-4. 